\title{
Nonlinear Exchange Rate Pass-Through to Domestic Prices in Ukraine
}

\author{
Oleksandr Faryna \\ National Bank of Ukraine \\ National University of "Kyiv-Mohyla Academy"
}

\begin{abstract}
This paper aims to estimate the degree of exchange rate pass-through (ERPT) to domestic prices in Ukraine considering nonlinearities with respect to the size and direction of exchange rate movements. We use disaggregated consumer price data and employ a panel autoregressive distributed lag model (ARDL) including threshold parameters to account for nonlinearities in the ERPT mechanism. We then compute dynamic ERPT coefficients taking into account inflation and exchange rate persistence. Estimation results suggest that the pass-through effect to core consumer prices is higher from currency depreciation than in the case of appreciation. On the contrary, we find that raw food prices are much more sensitive to appreciations. We also find that price responsiveness to small, medium, and large exchange rate changes is nonlinear. In particular, we provide evidence that prices are sensitive to small and extremely large changes, but the pass-through effect is insignificant if exchange rate movements are moderate.
\end{abstract}

\section{JEL Codes: E31, E52, E58, F31}

Keywords: exchange rate pass-through, inflation, Ukraine, nonlinear ERPT, Autoregressive Distributed Lag Model

\section{INTRODUCTION}

Exchange rate pass-through (ERPT) is traditionally defined as the percentage change in the price of imported good in local currency resulting from a one percent change in the nominal exchange rate. ${ }^{1}$ The puzzle of incomplete ERPT to import prices has become a trending research topic in theoretical and empirical literature since the breakdown of the Bretton Woods system. Furthermore, its importance from the monetary policy perspective extended the focus of such interest to capture the effect of exchange rate movements to all domestic price indices. Understanding the mechanism of exchange rate shocks transmission into domestic inflation might be a useful instrument for inflation forecasting, thus allowing the monetary authority to react efficiently to such shocks and maintain price stability.

Given the particular importance of the ERPT mechanism for open economies in transition, the literature on exchange rate pass-through in Ukraine is scarce. To our knowledge, few studies provide empirical estimates of ERPT for Ukraine (see Table 1). Korhonen \& Wachtel (2005) study ERPT to consumer prices in CIS countries. Authors use the VAR approach and impulse response analysis and estimate ERPT to consumer prices in Ukraine at a level of 0.63-0.64. Compared to other CIS countries, results for Ukraine are relatively high. Following a similar approach, Beckmann \& Fidrmuc (2013) provide ERPT estimates for seven CIS countries and confirm results for a high pass-through in Ukraine. They extend their analysis to measure US dollar and Euro exchange rates pass-through separately and find that Ukrainian prices are much more sensitive to US dollar exchange rate changes (0.45) than to Euro (0.25). Novikova \& Volkov (2012) employ a VEC framework and find that ERPT to core inflation in Ukraine amounts to a level of 0.35-0.47. 


\section{Table 1. ERPT for Ukraine in empirical literature}
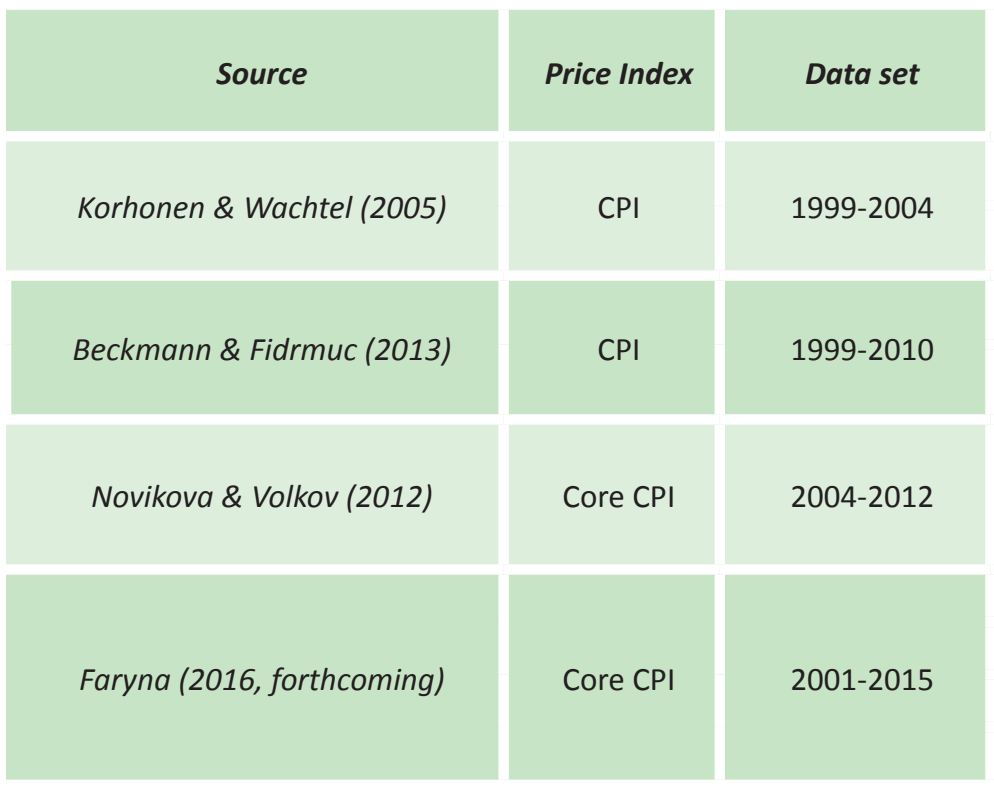

\begin{tabular}{|c|}
\hline Exchange Rate \\
\hline USD \\
\hline EUR \\
\hline USD \\
\hline EUR \\
\hline USD \\
\hline USD \\
\hline EUR \\
\hline NEER \\
\hline RUB \\
\hline
\end{tabular}

\begin{tabular}{|c|}
\hline Ukraine \\
\hline $0.63-0.64$ \\
\hline $0.24-0.28$ \\
\hline 0.45 \\
\hline 0.25 \\
\hline $0.35-0.47$ \\
\hline $0.40-0.42$ \\
\hline $0.20-0.21$ \\
\hline $0.27-0.28$ \\
\hline $0.09-0.10$ \\
\hline
\end{tabular}

Although empirical results are mixed, they all indicate a relatively high degree of exchange rate pass-through in Ukraine. However, all of these studies avoid, or include partially, analysis of ERPT asymmetry and nonlinearity. Therefore, in our paper we attempt to fill the gap in the literature and provide thorough evidence on the nonlinear exchange rate pass-through to consumer prices in Ukraine with respect to the size and direction of exchange rate changes. Following a well recognizable microfounded mark-up approach, we first employ a linear Autoregressive Distributed Lag Model (ARDL) and then extend the linear set-up by inclusion of nonlinear dummy parameters in order to capture asymmetries between appreciation and depreciation, as well as nonlinearities between small and large exchange rate changes. The degree of exchange rate pass through is then estimated using dynamic multiplier coefficients considering inflation and exchange rate persistence.

The rest of the paper proceeds as follows: a brief overview of the literature on ERPT and analytical framework of our analysis are presented in Sections 2 and 3 respectively; Section 4 provides an estimation approach and data description; estimation results can be found in Section 5; and then followed by conclusions in Section 6.

\section{BRIEF LITERATURE SURVEY}

In the following section, we draw on existing literature to discuss arguments on the nonlinear response of domestic prices to exchange rate fluctuations. We also review empirical evidence of ERPT asymmetry and nonlinearity across countries.

\section{A. Asymmetric pass-through from depreciation and appreciation}

The literature on ERPT asymmetry with respect to the direction of exchange rate changes generally consider a micro-founded "pricing to market" theory in explaining nonlinearities. Under this framework, the mark-up responsiveness from depreciation and appreciation has an opposite nature. More specifically, appreciation of an importing country's currency has a positive effect on a foreign exporter's mark-up and, thus, the absorption of exchange rate fluctuations (i.e., raising the mark-up and keeping constant prices expressed in an importing country's currency) is more desirable. In the case of depreciation of an importer's currency, a foreign exporter has an incentive to pass through exchange rate changes and raise prices in order to maintain stable profits.

However, as discussed in Pollard \& Coughlin (2004) and Marston (1990), assuming that foreign producers care about their market share, exporting firms are likely to pass-through exchange rate appreciation and decrease prices, expressed in the currency of the importer, in order to gain market share. Depreciation, in turn, will not be reflected in domestic prices given that foreign firms may never raise prices above the price of a substitute good in the importing country's market in order to hold on to market share. Hence, in a competitive environment, the response of domestic prices to exchange rate appreciation is higher than in cases of depreciation. 
On the contrary, in a climate of imperfect competition, a foreign producer has a high market share in the destination market and, thus, has substantial pricing power. Bussiere (2007) and Delatte \& Lopez-Villavicencio (2012) argue that the higher the market share, the lower the incentive of an exporter to absorb exchange rate depreciation (i.e., to keep constant prices in an importer's currency and decrease profits) and to pass-through appreciation (i.e., decrease prices and keep fixed profits). In this case, imperfect competition implies that prices are more sensitive to depreciations than to appreciations.

\section{B. Nonlinear pass-through from small and large exchange rate changes}

The effect form small and large exchange rate movements might also be nonlinear. Pollard \& Coughlin (2004) explain such nonlinearities by the presence of menu costs. Assuming that the change of the invoice price is costly for an exporting firm, ERPT from small and large changes may differ. In this case, the type of pricing strategy matters (i.e., local currency pricing vs. producer currency pricing). The invoice price changes if the exchange rate change is above a certain threshold level.

Under the producer currency pricing (PCP) strategy, the invoice price is set in the exporter's currency. A foreign firm may not adjust its invoice prices due to a small exchange rate change, which implies that prices expressed in an importer's currency will fully reflect exchange rate movements. In this case, ERPT is complete. However, in order to react on demand conditions and maintain a market share, exporters may absorb a part of the exchange rate pressure from large changes and adjust prices in their currency, thus reducing the degree of pass-through to prices in an importing country's currency.

On the contrary, under the local currency pricing (LCP) strategy, the invoice price is set in the importer's currency. In this case, import prices in domestic currency do not respond to small exchange rate changes. If the change is large, a foreign firm may adjust the price and increase the level of pass-through. Hence, LCP strategy implies that ERPT is higher when exchange rate changes are large than when they are small.

Different price-setting behaviors of exporting firms can be captured in empirical analysis by examining exchange rate passthrough to prices set in producer and local currencies separately. This requires a highly disaggregated and informative data range that is usually unavailable. In our analysis, we assume that producer currency pricing is prevalent in the case of Ukraine and, thus, following theoretical arguments, we can expect that aggregate domestic prices should be more sensitive to smaller rather than to larger exchange rate changes.

\section{Empirical evidence}

Theoretical literature is not straightforward in explaining the direction of ERPT asymmetry from depreciation and appreciation of different size. Moreover, empirical studies are not conclusive either. There is vast literature that confirms the presence of nonlinearities on the industry level and finds that the direction of asymmetry varies across industries.

Campa et al. (2005) use disaggregated data from EU countries and find that the extent to which import prices in manufacturing industries respond to appreciation episodes is higher than in the case of depreciation. In contrast, a symmetric response of prices for agriculture and commodity imports cannot be rejected. Pollard \& Coughlin (2004), in turn, provide ERPT estimates for 30 manufacturing industries and find that the degree of pass-through is positively related to the size of the exchange rate change. However, they also show that prices respond asymmetrically to appreciation and depreciation only in few industries and the direction of asymmetry varies. Bussiere (2007) also supports the presence of nonlinearities in ERPT. The author analyzes aggregate import prices in G7 counties and finds strong evidence of asymmetric ERPT, although the direction of asymmetries varies across countries. Nogueira \& Leon-Ledesma (2008) use aggregate consumer price data for six countries under inflation targeting regime and provide evidence that the magnitude of exchange rate variations is a driving factor of nonlinearities for some countries. Delatte \& López-Villavicencio (2012) also find that CPI response to exchange rate depreciation is higher than to appreciation in four developed countries.

To sum up, empirical literature provides strong evidence showing that nonlinearities in the pass-through mechanism cannot be neglected both for import prices, as well as for consumer prices. Given this fact, we attempt to relax the assumption of symmetric and linear ERPT to domestic prices in the case of Ukraine. 


\section{ANALYTICAL FRAMEWORK}

In this section, we briefly outline the analytical framework that we use to estimate exchange rate pass-through to consumer prices in Ukraine. We employ a standard micro-founded mark-up approach, commonly utilized in literature, as a starting point for our analysis. ${ }^{2}$ We then adapt it to estimate ERPT to consumer prices considering nonlinearities with respect to the size and direction of exchange rate changes.

Consider a single Foreign firm that sells a specific product to Home country and has pricing power in the importing country's market. The pricing behavior of a firm may be expressed by a simple profit-maximization problem:

$$
\max _{P^{H}} \pi=\frac{P^{H} Q}{E}-C(Q),
$$

where $\boldsymbol{\pi}$ is the exporting firm's profit in Foreign currency; $\boldsymbol{E}$ is the exchange rate of Home currency per unit of the exporting firm's currency; $\boldsymbol{P}^{H}$ is the price in Home currency; $C(Q)$ is the cost function in the Foreign currency, and $\boldsymbol{Q}$ is the quantity demanded.

The first-order condition of the equation (1) yields to the following form:

$$
P_{t}^{H}=E_{t} \mu_{t} C_{t}^{F}
$$

where $\boldsymbol{C}_{\boldsymbol{t}}^{\boldsymbol{F}}$ is the marginal cost of the exporting firm and $\boldsymbol{\mu}_{\boldsymbol{t}}$ is the mark-up over marginal cost. Equation (2) implies that the price of a product in Home currency may vary due to independent changes in the nominal exchange rate, Foreign firm's marginal cost, and mark-up, which, in turn, is assumed to depend on the demand conditions in the Home market $-\boldsymbol{Y}$.

In addition, we test in our analysis the hypothesis that mark-up responsiveness is asymmetric. More specifically, a foreign firm's decision whether to absorb or pass-through exchange rate depreciation may be different than in the case of appreciation. Incorporating these arguments, we consider the transition function $\boldsymbol{\gamma}(\boldsymbol{D})$ representing the nonlinear channel of ERPT with respect to the direction of exchange rate variations, where $D=\Delta e_{t-i}$ is the percentage change of the exchange rate. Thus, a foreign firm's mark-up can be expressed in the following functional form:

$$
\boldsymbol{\mu}_{t}=\boldsymbol{\mu}\left(\boldsymbol{Y}, \boldsymbol{E}^{\gamma(\boldsymbol{D})}\right) \text {. }
$$

Consequently, according to equation (2) and (3), a simple log-linear reduced-form ERPT equation would be ${ }^{3}$ :

$$
p_{t}^{H}=\alpha+\beta e_{t}+\gamma(D) e_{t}+\delta c_{t}^{F}+\rho y_{t}^{H}+\varepsilon_{t}
$$

Assuming that there is a threshold value of exchange rate change $D^{*}=0$, which divides extreme cases into regimes of appreciation and depreciation, the function $\gamma(D)$ may be further defined in the following way:

$$
\gamma(D)= \begin{cases}0, & \text { if } D>D^{*} \\ \varphi, & \text { otherwise }\end{cases}
$$

Inclusion of the transition function to our model enables the estimation of two different ERPT coefficients. From equation $(4)$, the joint ERPT coefficient is measured as $(\boldsymbol{B}+\boldsymbol{v}(\boldsymbol{D}))$. Hence, if the exchange rate depreciates and $\boldsymbol{D}>\boldsymbol{D}^{*}$, the degree of passthrough is $(\boldsymbol{B}+\boldsymbol{0}=\boldsymbol{B})$. However, in the case of appreciation, when $\boldsymbol{D} \leq \boldsymbol{D}^{*}$, ERPT is $(\boldsymbol{B}+\boldsymbol{\varphi}) .^{4}$

Following a similar approach, we consider nonlinearities in the pass-through mechanism with respect to the size of exchange rate movements. As described in section 2.B. of this paper, the presence of menu costs and different pricing strategies may affect a firm's decision on mark-up adjustment after small and large exchange rate movements. In this case, $D^{*}$ represents some threshold value below and above which exchange rate variations are assumed to be small and large, respectively. Hence, $\boldsymbol{B}$ measures the pass-through of a large exchange rate change, while $(\boldsymbol{b}+\boldsymbol{\varphi})$ measures the pass-through of a small change.

\footnotetext{
${ }^{2}$ For example, as in Goldberg \& Knetter (1997).

${ }^{3}$ Equation (4) is similar to one in Cheikh (2013) and Nogueira \& Leon-Ledesma (2007), where component $\gamma(D)$ was used to represent the business cycle and macroeconomic stability conditions in the destination country.

${ }^{4}$ The sign of $\phi$ indicates the direction of asymmetry, i.e., whether the transmission of exchange rate is higher or lower after depreciation and appreciation.
} 
The framework presented above describes the process of price adjustment from a microeconomic perspective and is usually used in literature to estimate exchange rate pass-through to import prices of tradables in specific industries. Nevertheless, we use it as a starting point and extend the model so that it is suitable to estimate ERPT to consumer prices. As argued in Bailliu \& Fujii (2004), a common assumption in empirical literature is that the aggregate price level and exchange rate follow nonstationary processes. Differentiation of variables expressed in logarithms results in the estimation of an inflation equation. In addition, following literature on inflation and ERPT to aggregate consumer prices, we also include inflation persistence to account for adaptive expectations. ${ }^{5}$ Furthermore, lagged values of other independent variables should be considered in order to capture the relationship in dynamics. Incorporating these arguments, equation (4) can be re-written as follows:

$$
\Delta p_{t}^{H}=\alpha+\sum_{i=1}^{n} \theta_{i} \Delta p_{t-i}^{H}+\sum_{i=0}^{k}\left(\beta_{i}+\gamma(D)\right) e_{t-i}+\sum_{i=0}^{q} \delta_{i} c_{t-i}^{F}+\sum_{i=0}^{r} \rho_{i} y_{t-i}^{H}+\varepsilon_{t}
$$

\section{ESTIMATION APPROACH AND DATA DESCRIPTION}

Considering a theoretical inflation equation (6) described in the previous section, we employ an ARDL model in our econometric set-up. A simple reduced-form $\operatorname{ARDL}(n, k)$ model can be presented as follows:

$$
Y_{t}=a_{0}+\sum_{i=1}^{n} a_{1, i} Y_{t-i}+\sum_{i=0}^{k} a_{2, i} X_{t-i}+\varepsilon_{t}
$$

where $\boldsymbol{Y}_{\boldsymbol{t}}$ is the dependent variable, $\boldsymbol{X}_{\boldsymbol{t}}$ represents an independent variable, $\boldsymbol{a}_{1, i}$ and $\boldsymbol{a}_{2, i}$ are parameters of the model, $\boldsymbol{a}_{\boldsymbol{0}}$ is a constant, and $\varepsilon_{t}$ is white noise.

An ARDL model can be easily estimated by ordinary list squares using lag selection criterions (e.g., Akaike, Shwarz, HannanQuinn information criteria). Interpretation of the coefficients in equation (7), where all variables are in first differences and in logarithms, is straightforward, indicating a percentage change of a dependent variable resulting from a $1 \%$ change of each regressor. In the case of ERPT estimation (i.e., when the dependent variable is inflation, and the independent is the exchange rate change), in order to account for the dynamic effect, we compute dynamic multiplier coefficients considering inflation persistence and past exchange rate movements.

Our analysis is based on the monthly frequency data and captures the period from January 2007 to April $2016 .{ }^{6}$ The data choice is based on the consideration of theoretical framework hypothesis, described in previous sections. Following a markup approach, we use disaggregated data of consumer prices (i.e., 258 indices) in Ukraine and estimate the nonlinear effect of exchange rate changes for the set of price groups separately, including:

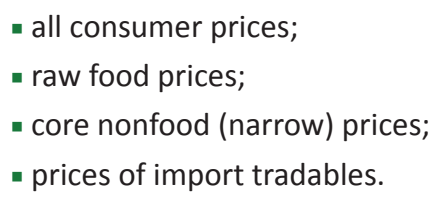

$$
\begin{aligned}
& \text { - core consumer prices; } \\
& \text { - core food prices; } \\
& \text { - prices of tradables; and }
\end{aligned}
$$

We use several price groups in our analysis in order to capture peculiarities of different consumer price indices. In particular, the group of "all consumer prices" includes prices of all goods and services. "Core consumer prices" excludes raw food prices, administratively regulated prices and services, and fuel prices. Moreover, following the analytical framework of our analysis, which aims to explain the pass-through effect to prices of goods, we also estimate the response of core food and nonfood prices excluding services. Finally, the pricing-to-market theory assumes that exporting firm's mark-up responsiveness may depend on demand conditions in the importing country and prices of domestically produced substitutes. Hence, we narrow the analysis to study the pass-through effect to prices of tradable goods. In addition, we also examine import tradables, which may be particularly sensitive to exchange rate movements. All price indices are normalized (December $2006=100$ ) and seasonally adjusted using an X-12 additive monthly seasonal adjustment method.

Korhonen \& Wachtel (2005) argue that the US dollar exchange rate is one of the most important relative prices in most CIS countries, including Ukraine. In addition, Coibion \& Gorodnichenko (2015) highlight the importance of the USD to UAH exchange rate for households' expectations. However, as a result of the exchange rate peg to the US dollar, a USD/UAH time

\footnotetext{
${ }^{5}$ Nogueira \& Miguel (2007) present an extension of the mark-up model for the case of consumer prices including inflation persistence and output gap to match Phillips curve.

${ }^{6}$ Data source: National Bank of Ukraine Statistics and State Statistics Service of Ukraine.
} 
series includes only several appreciation episodes and three stages of rapid depreciation in 2008, 2014, and 2015, which makes the estimation of nonlinearities problematic. On the contrary, the nominal effective exchange rate (NEER) is more volatile as it includes trade-weighted exchange rates of other countries. Thus, in our empirical analysis, the exchange rate variable is an inverted normalized NEER of domestic currency per unit of weighted foreign currencies (December 2006 = 100). A positive change in NEER indicates depreciation, while negative changes represent episodes of appreciation.

In order to account for demand conditions in an importing country, we use the Industrial Production Index gap (IPI), ${ }^{7}$ which is available on a monthly basis. Foreign producer costs, which, in turn, reflect supply conditions, are commonly expressed by inclusion of energy prices (e.g., oil prices), as in Koichi (2013), Delatte \& López-Villavicencio (2012), and McCarthy (2000, 2007). Thus, we use the Fuel Price Index (FPI) ${ }^{8}$ from the IMF Commodity Price Statistics in our analysis. All time series are in logarithms.

Following the above mentioned theoretical framework and estimation approach, we start with estimation of the baseline linear ARDL model to measure ERPT to consumer price indices. The lag length of each variable in the equation was selected using a "general to specific" approach and AIC statistics, resulting in the following ARDL specification:

$$
C P I_{t}=a_{0}+\sum_{i=1}^{3} a_{1, i} C P I_{t-i}+\sum_{i=0}^{3} a_{2, i} N E E R_{t-i}+\sum_{i=1}^{2} a_{3, i} I P I_{t-i}+\sum_{i=0}^{2} a_{4, i} F P I_{t-i}+\varepsilon_{t}
$$

We then use a baseline linear set-up model and add nonlinear elements to account for asymmetry with respect to direction and size of exchange rate movements (as in Pollard \& Coughlin (2004)). Firstly, we include two dummy variables $\boldsymbol{D}^{+}$and $\boldsymbol{D}^{-}$, which reflect periods of depreciation and appreciation, and estimate ERPT coefficients for different regimes separately. Then we repeat this procedure with dummy variables that reflect periods of small and large exchange rate changes. In order to test for a linearity hypothesis, we use the Wald-test imposing coefficient restrictions $\boldsymbol{\beta}_{D^{+}}=\boldsymbol{\beta}_{D^{*}}$.

Before discussing estimation results, an important issue on the choice of a transition variable and the threshold value should be raised. A transition variable is used to divide the exchange rate time series on several regimes (e.g., depreciation and appreciation, or small and large changes). Empirical literature on ERPT asymmetry (as in Pollard \& Coughlin (2004)) commonly use a percentage change of the exchange rate variable utilized in the regression equation as a transition variable. More specifically, within a monthly-based analysis, the sign of a monthly exchange rate change is used to divide a data set into regimes of depreciation and appreciation (i.e., $\Delta \boldsymbol{e}_{t-1}>\mathbf{0}$ and $\Delta \boldsymbol{e}_{t-1}<0$ ). However, one would argue that a transition variable should reflect exchange rate movements over some longer period in the past. In particular, the transition from one regime to another may not be instant. In our analysis, we choose a transition variable which covers all lagged values of the exchange rate in the inflation equation. In particular, the inclusion of three lags of exchange rate implies that the transition variable is the NEER quarterly percentage change ( $\Delta$ neer $\left.{ }_{t-3}\right)$.

Another important issue in the estimation of nonlinear ERPT is the choice of a threshold value. While for the direction of exchange rate movements a threshold value simply equals zero, a measurement of the size of exchange rate changes requires additional assumptions. Pollard \& Coughlin (2004) use an arbitrarily chosen threshold value of $3 \%$ in their analysis. In contrast, a set of empirical ERPT studies use Threshold Autoregressive models (TAR) or Smooth Transition Regressions (STR) in order to determine a threshold value endogenously. ${ }^{9}$

In order to measure asymmetries and nonlinearities in the ERPT mechanism for Ukraine with respect to the direction and size of exchange rate movements, we use several alternative threshold values (see Figure 2):

- Depreciation and appreciation periods are simply split by a threshold value which equals zero. This results in the division of the total number of observations into $61 \%$ of depreciation and $39 \%$ of appreciation episodes.

- To measure the magnitude of exchange rate variations, we first use a median of the absolute values of the quarterly NEER change, which approximately equals $3 \%$ (i.e., MED. $=0.0325$ ). Using the median allows for the division of the data set into two equal periods.

- Additionally, in the alternative model specification we use two standard deviations as a threshold value which approximately equals $16 \%$ (i.e., S.D. $=0.0794$ ). This helps to capture extremely large depreciation episodes in 2008, 2014 , and 2015. Although the fraction of extreme cases is $9 \%$, the panel dimension enables the estimation of the ERPT coefficient with a relatively low number of observations.

- Lastly, we use both threshold values of $3 \%$ and $16 \%$ to divide time series of the quarterly NEER change to periods of small changes (i.e., abs $\left(\Delta\right.$ neer $\left._{t-3}\right)<3 \%$ ), large changes (i.e., $a b s\left(\Delta\right.$ neer $\left.\left._{t-3}\right)>16 \%\right)$, and medium changes (i.e., $3 \%<a b s\left(\Delta\right.$ neer $\left.\left._{t-3}\right)<16 \%\right)$.

\footnotetext{
${ }^{7}$ The IPI gap is calculated by taking the difference of seasonally adjusted IPI and HP-filtered IPI in logarithms.

${ }^{8} \mathrm{FPI}$ includes Brent oil, natural gas, and coal prices.

${ }^{9}$ For example, Shintani (2009) uses a grid search approach to determine a threshold value.
} 
Figure 1. Transition variable (1 quarter NEER change) and threshold values
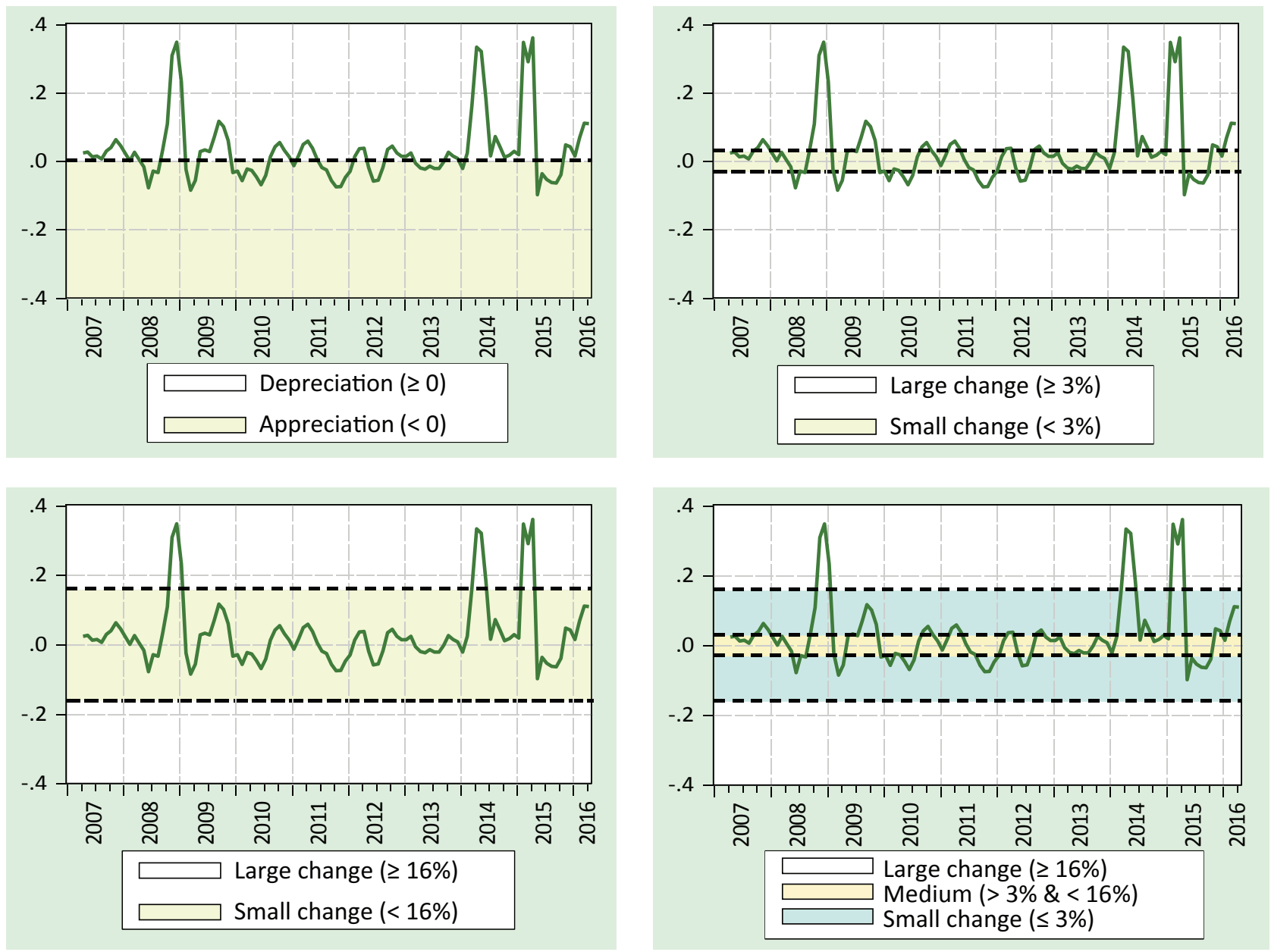

\section{ESTIMATION RESULTS}

Estimated coefficients were used to calculate the dynamic multiplier measuring the cumulative ERPT effect. Figure 2 shows the response of core consumer prices to a $1 \%$ NEER change. The left graph represents the effect on the price change (i.e., inflation) at each point in time, while right graph shows the accumulated response of prices.

Exchange rate pass-through for the group of all consumer prices is estimated at a level of 0.172 , which is in line with existing empirical studies for Ukraine. The response of core prices, prices of tradables, and import tradables is 0.181-0.189. For core food prices, the ERPT coefficient is somewhat higher -0.268 , while prices of core nonfood goods have the lowest pass-through of 0.154 . Interestingly, in the short-run, the degree of exchange rate pass-through ERPT for raw food prices rises to 0.24 , which is the highest compared to other price groups, and subsequently stabilizes at a level of 0.183. All ERPT coefficients are statistically significant at a $1 \%$ confidence level.

In the next step of our analysis, we estimate several nonlinear models considering different direction and size of exchange rate changes. Table 2 reports the summary results from a linear and four nonlinear ARDL specifications. 
Figure 2. Linear price responsiveness to $1 \%$ NEER change

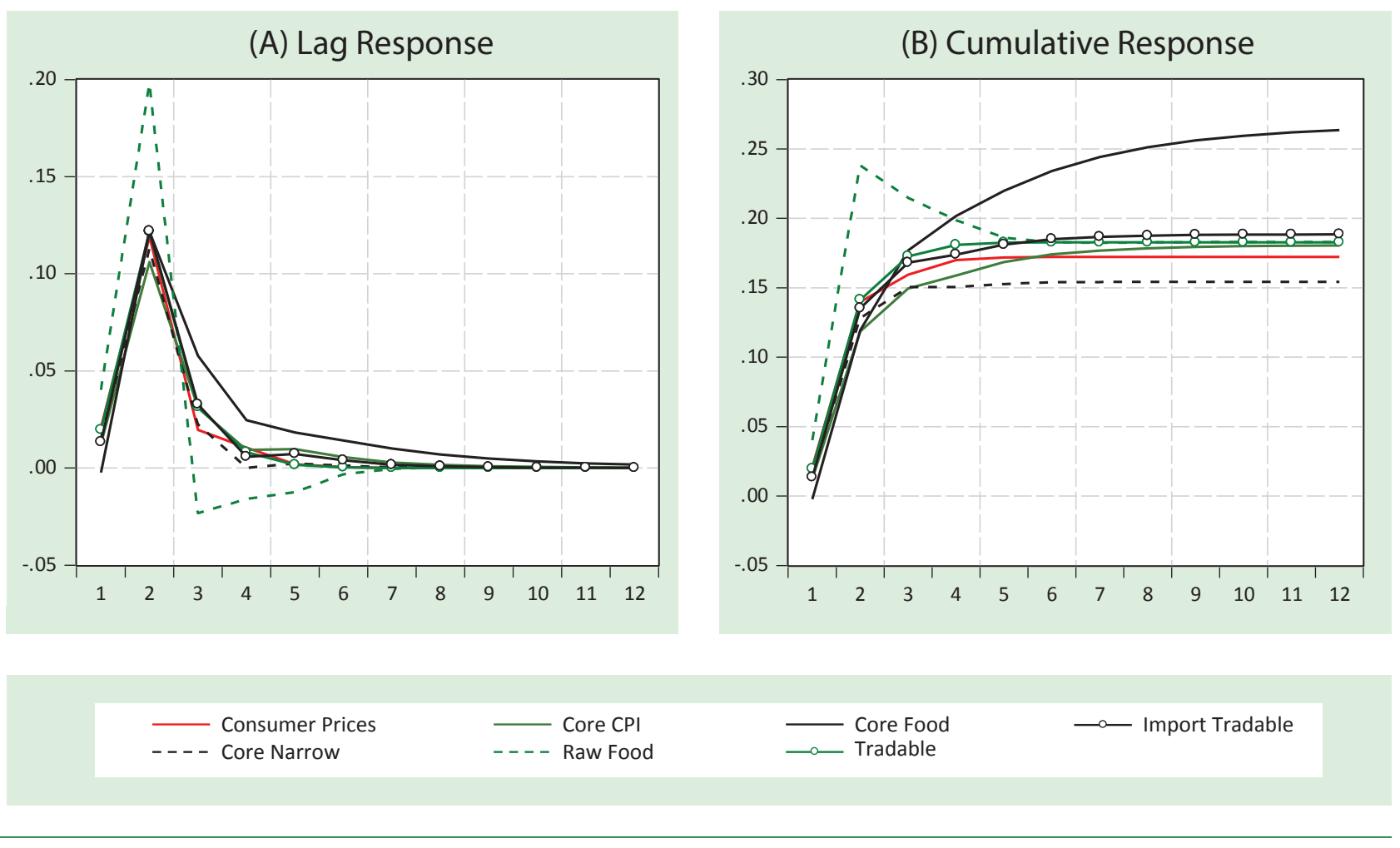

\section{A. Direction of exchange rate movements}

Figure 3 shows the cumulative price responsiveness to a one percent NEER depreciation and appreciation. Estimation results suggest that exchange rate pass-through is asymmetric with respect to the direction of NEER change for most of price groups. In particular, depreciation passes through to a larger extent than appreciation in the case of all consumer prices, core consumer prices, core nonfood prices, and prices of tradables and import tradables. These results are in line with the "pricingto-market" theory in a climate of imperfect competition. In this respect, foreign exporting firms have market power over importing countries' market and tend to adjust their mark-ups in response to appreciations, thus keeping fixed prices and rising profits. On the contrary, following depreciation of an importing country's currency, foreign producers have an incentive to raise prices and keep stable profits. Compared to the linear ARDL model, the degree of ERPT from depreciation is larger and varies from 0.221 for all consumer prices to 0.299 for the group of import tradables. Interestingly, ERPT from appreciations in some cases has a negative sign (i.e., currency appreciation increases domestic prices). As argued in Faryna (2016, forthcoming) this can be a result of sufficient cross-country spillovers in the ERPT mechanism. In particular, the pass-through effect from appreciation may be compensated by allowing for a higher order transmission channels between several countries.

In the case of raw food prices, ERPT asymmetry has an opposite direction. We find that a one percent NEER appreciation results in a 0.728 percent decline in prices of raw foods. Following theoretical assumptions, these results indicate much better competition conditions for such type of goods. Although the ERPT coefficient is statistically significant at a $99 \%$ confidence level, raw foods are usually sensitive to other external factors (e.g., crop yielding capacity) that are not considered in our analysis and may bias results. For the group of core food prices, the linearity hypothesis cannot be rejected, indicating no asymmetry in the ERPT mechanism.

\section{B. Size of exchange rate movements}

To study nonlinearities with respect to the magnitude of exchange rate movements, we first estimate the nonlinear ARDL model with a threshold value of $3 \%$. For most price groups, the linearity hypothesis is strongly rejected while results suggest that small NEER changes pass through to consumer prices to a larger extent than in the case of large changes. However, using a threshold value of a 16\% NEER change in the alternative NARDL specification results in the opposite direction of price responsiveness. In particular, we find that ERPT from extremely large NEER changes is larger. 
These results indicate that ERPT nonlinearities with respect to the size of exchange rate change may include more than one threshold value. Thus, we estimate the model allowing for small, medium, and large NEER changes. Figure 3 shows the cumulative price responsiveness considering three regimes. Results show that for most price groups, extremely large as well as small NEER changes have a considerable effect on consumer prices. Moreover, the linearity hypothesis cannot be rejected for core consumer prices, core food and nonfood prices, and prices of import tradables. On the contrary, medium NEER changes are statistically insignificant in all cases.

Considering theoretical arguments on ERPT nonlinearity, our results indicate the presence of menu costs, which implies that foreign exporting firms following a producer currency pricing strategy may not adjust their prices in response to small exchange rate changes. On the contrary, foreign producers may absorb the pressure from relatively larger exchange rate movements in their mark-ups in order to keep stable profits in the case of depreciation of the destination country's currency and in order to maintain or gain market share in the case of appreciation. Moreover, as argued in Nogueira \& Leon-Ledesma (2011), exchange rate pass-through can be higher in periods of financial or confidence crises, when firms have no incentive to absorb cost increases in their margins. This is in line with our estimates for Ukraine as extremely large exchange rate depreciation episodes where experienced under crisis conditions resulting in high ERPT.

\section{CONCLUDING REMARKS}

From the beginning of 2014, Ukraine has experienced a rapid depreciation of the hryvnia caused by dramatic shifts in the risk premium, adjustments to balance of payment mismatches, and unfavorable terms of trade, all of which aggravated macroeconomic turbulences and, eventually, resulted in peek inflation up to $60 \%$. Since 2015, the National Bank of Ukraine has declared a new direction for its monetary policy on inflation targeting (IT). In a climate of gradual economic stabilization and a floating exchange rate regime, the hryvnia depreciated by around $20 \%$. In contrast to past periods, it was mainly due to a drop in world commodity prices and imposed trade restrictions with Russia. In this case, the decrease of commodity prices had both a positive and negative effect on the aggregate price level. This, eventually, resulted in a relatively modest price adjustment.

Nevertheless, the adoption of IT and transition to a flexible exchange rate in a small open economy may be problematic if the risks associated with exchange rate volatility remain high. Hence, the ability of the NBU to attain its inflation targets requires a thorough understanding of the extent to which consumer prices respond to exchange rate movements.

Given the particular importance of exchange rate pass-through, literature that explores this issue in Ukraine is scarce. Although there are several comprehensive studies that provide empirical estimates for Ukraine, the time span of their analysis can be characterized by the period of the exchange rate peg to the US dollar, which was used to provide a nominal anchor for the economy. In this paper, we fill the gap in the literature by examining exchange rate pass-through issues in Ukraine. In particular, we attempt to answer the question of what extent consumer prices in Ukraine respond to depreciations and appreciations of different magnitude.

Following a standard mark-up approach, we find that in most price groups the pass-through effect from depreciation is higher than from appreciation, indicating weak competition in Ukraine. Additionally, we find that small changes have a considerable effect on price adjustments in Ukraine, while moderate changes are statistically insignificant. Given that foreign firms most often follow a producer currency pricing strategy while exporting goods to Ukraine, our results indicate the presence of menu costs for foreign producers. In addition, we find that the pass-through effect rises in the case of extremely large exchange rate depreciations. To sum up, the National Bank of Ukraine, while attaining its inflation targets, should be aware that consumer prices in Ukraine are sensitive to small and extremely large nominal effective exchange rate changes, while the pass-through effect is statistically insignificant in the case of moderate NEER fluctuations.

In addition to asymmetries and nonlinearities with respect to the direction and magnitude of exchange rate changes, empirical literature finds other sources of nonlinearities in the ERPT mechanism (e.g., inflation environment, business cycles, exchange rate volatility). Hence, studying these issues for Ukraine may be the subject of further research 
Table 2. Estimated exchange rate pass-through coefficients

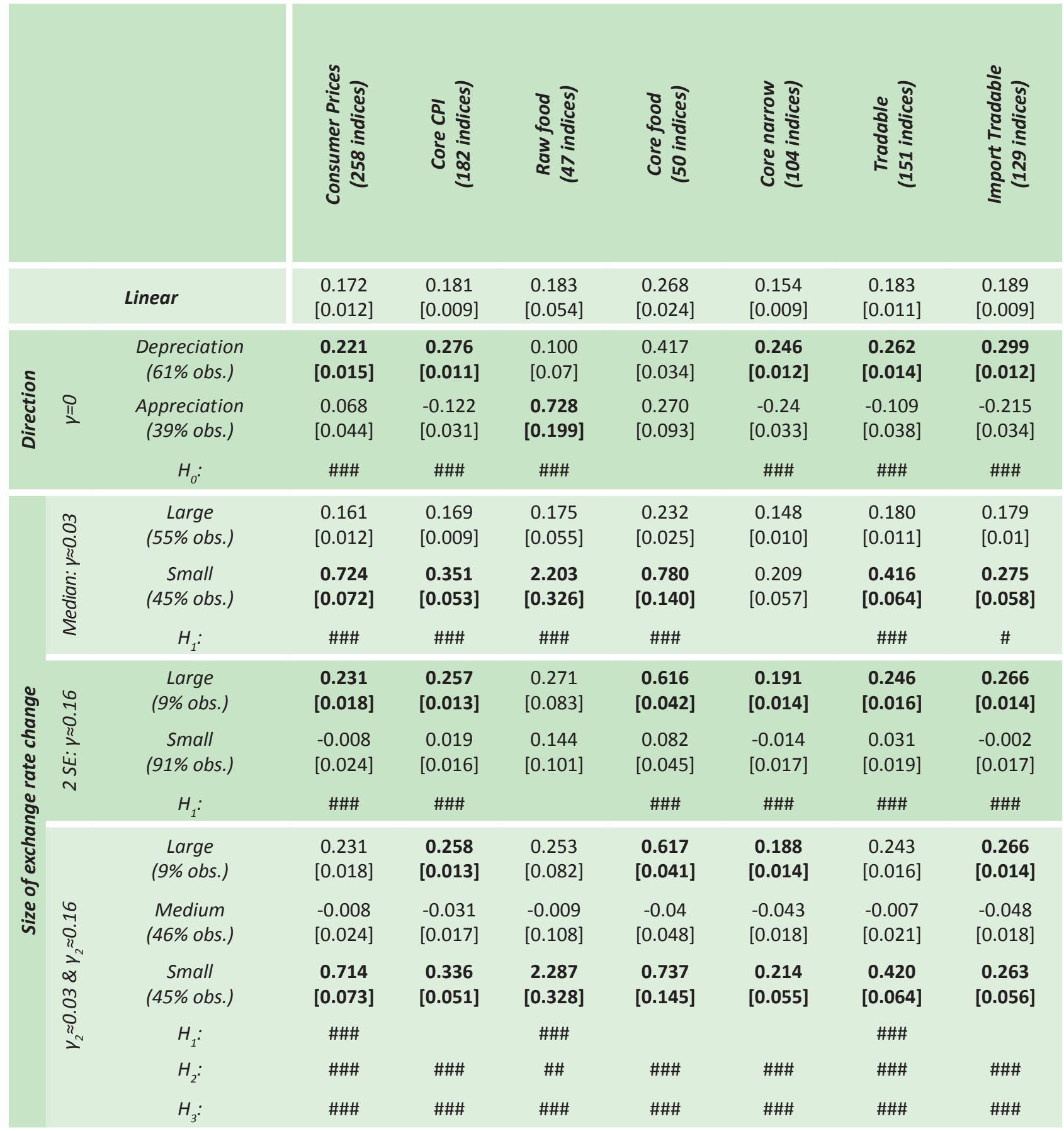

Notes: numbers are ERPT coefficients; numbers in [ ] are standard errors; $\gamma$-threshold value.

\#\#\#, \#\#, \# indicate 1, 5, 10 \% significance level to reject linearity hypotheses:

$\mathrm{H}_{0}$ : depreciation = appreciation

$\mathrm{H}_{1}$ : large $=$ small

$\mathrm{H}_{2}$ : large $=$ medium

$\mathrm{H}_{3}$ : medium $=$ small 
Figure 3. Price responsiveness to $1 \%$ NEER depreciation and appreciation

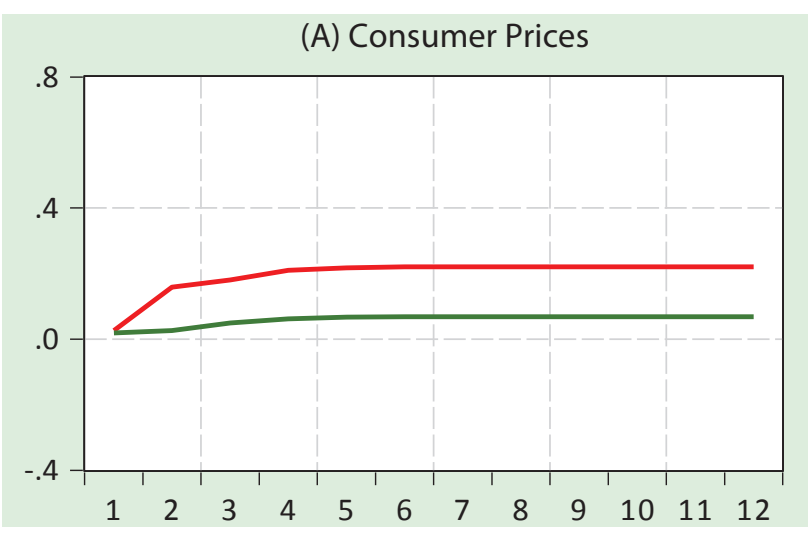

(B) Core Consumer Prices

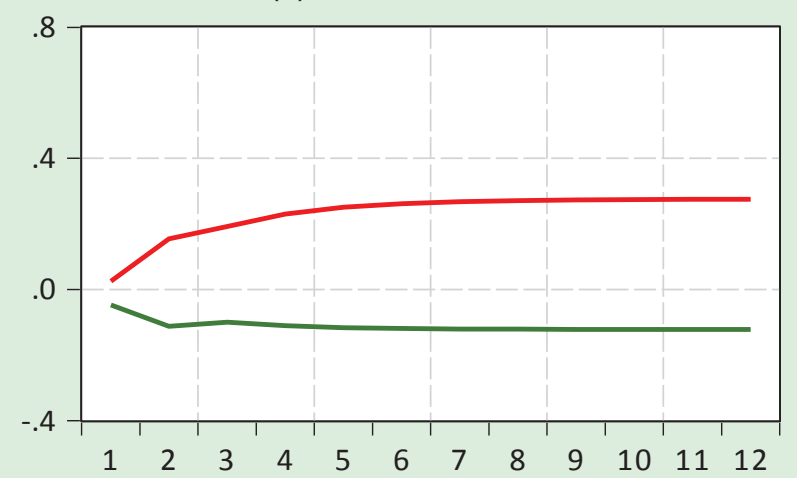

(C) Core Food Prices

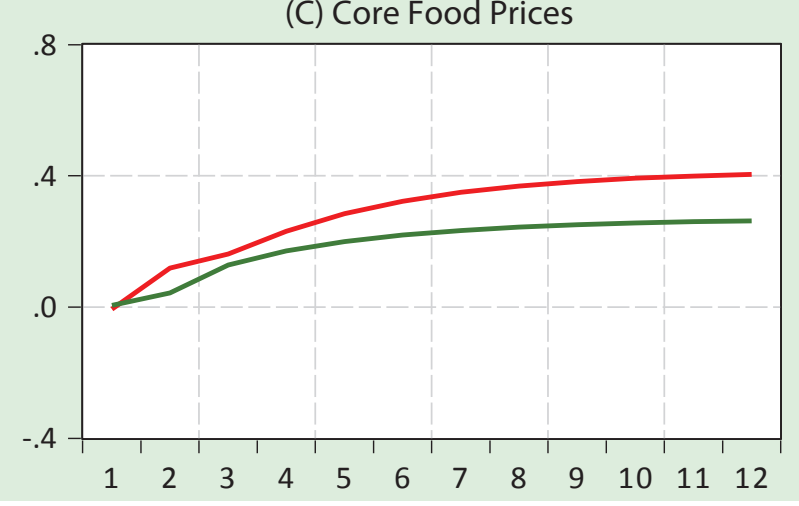

(E) Prices of Tradables

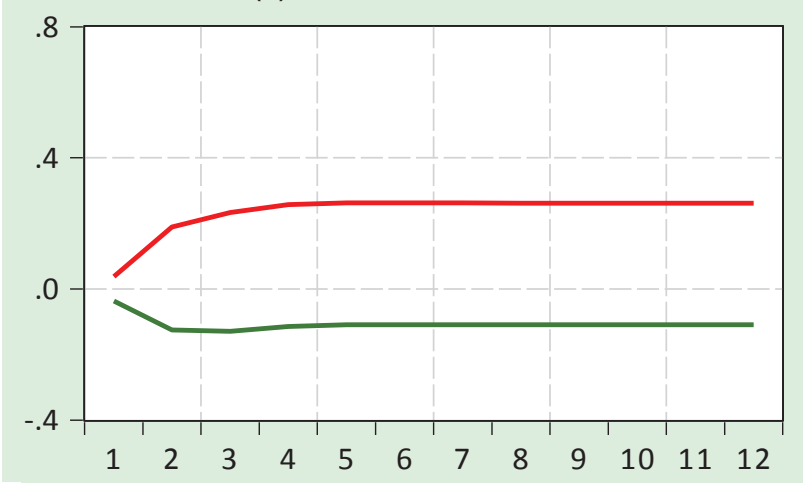

Depreciation $(\geq 0)$

Appreciation (<0)

(D) Raw Food Prices

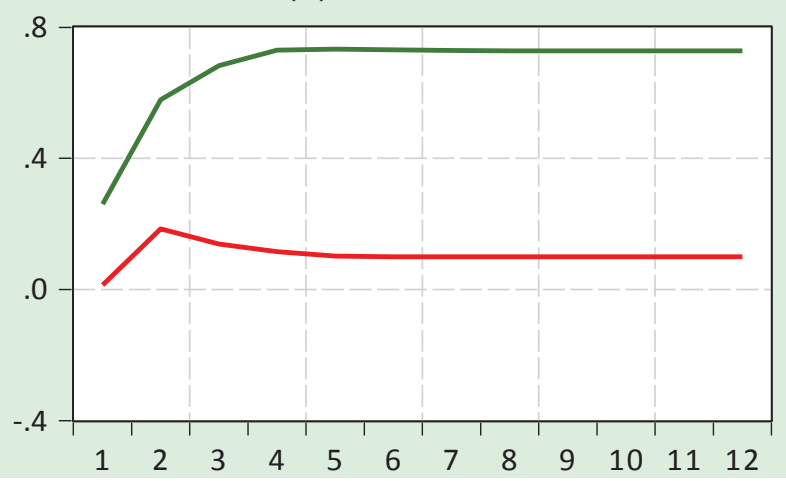

(D) Core Narrow Prices

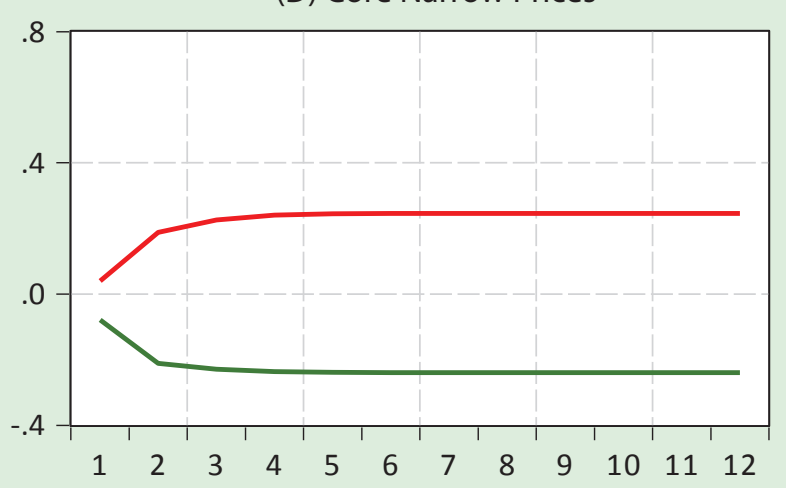

(F) Prices of Import Tradables

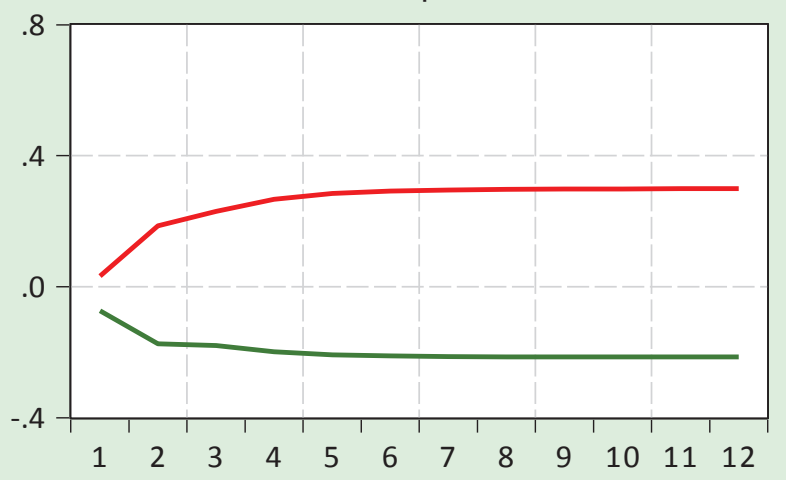

Note. Figures plot cumulative dynamic exchange rate pass-through coefficients for 12 month. 
Figure 4. Price responsiveness to large, medium, and small NEER changes

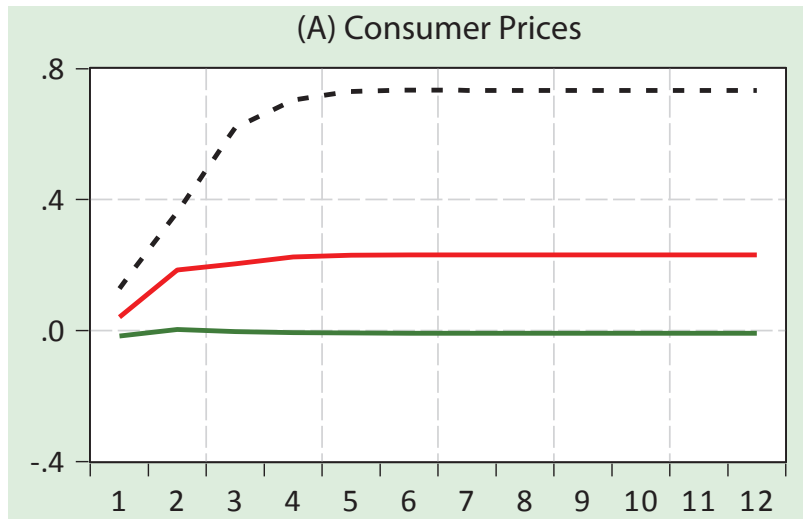

(B) Core Consumer Prices

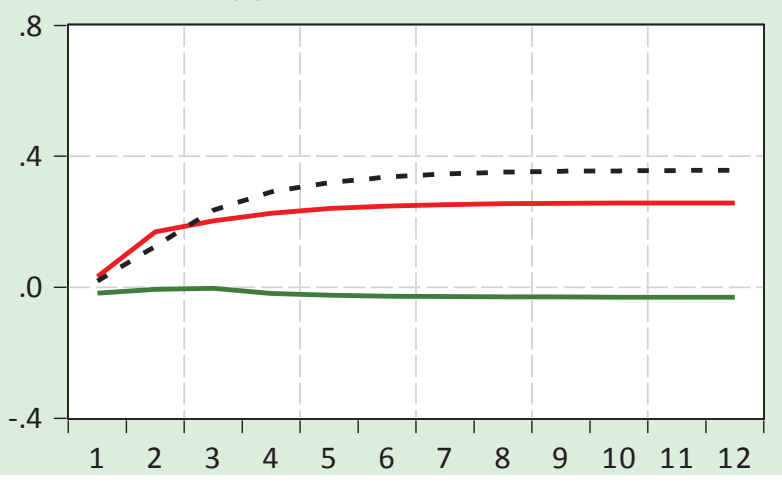

(D) Core Food Prices

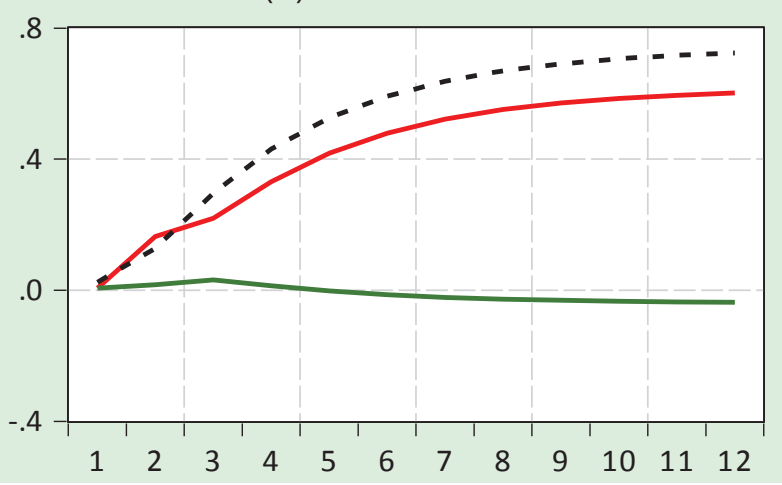

(F) Prices of Tradables

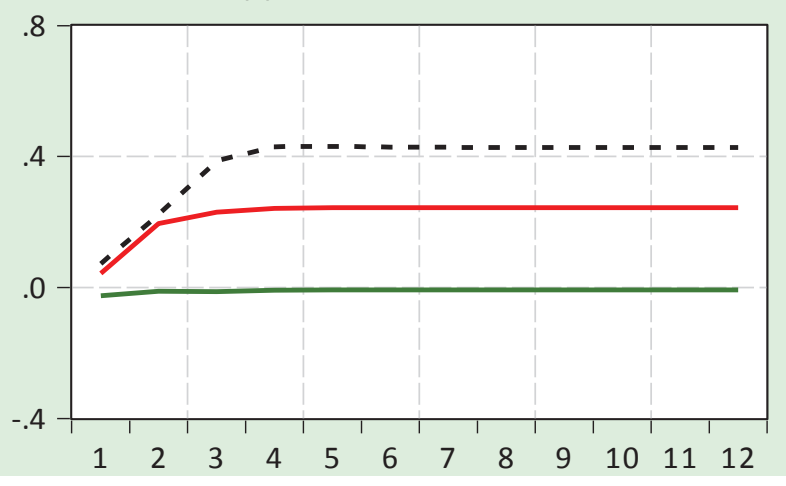

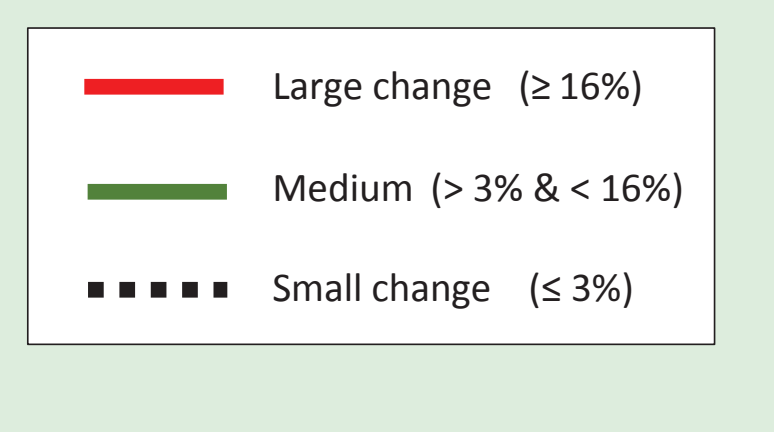

(C) Raw Food Prices

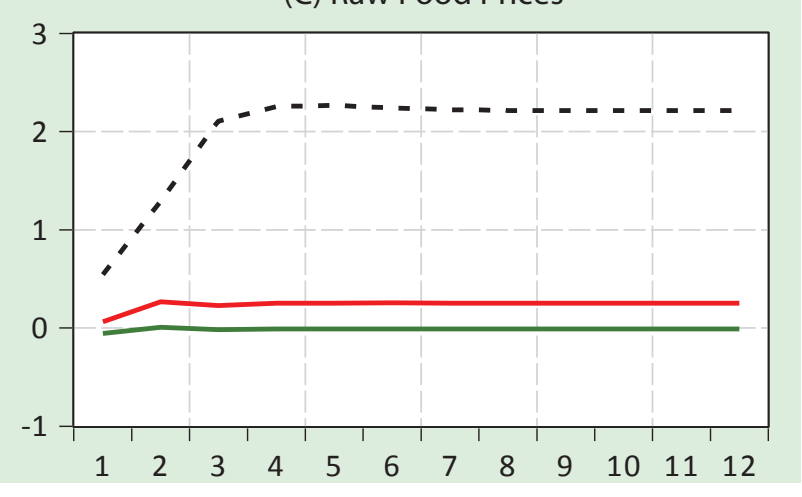

(E) Core Narrow Prices

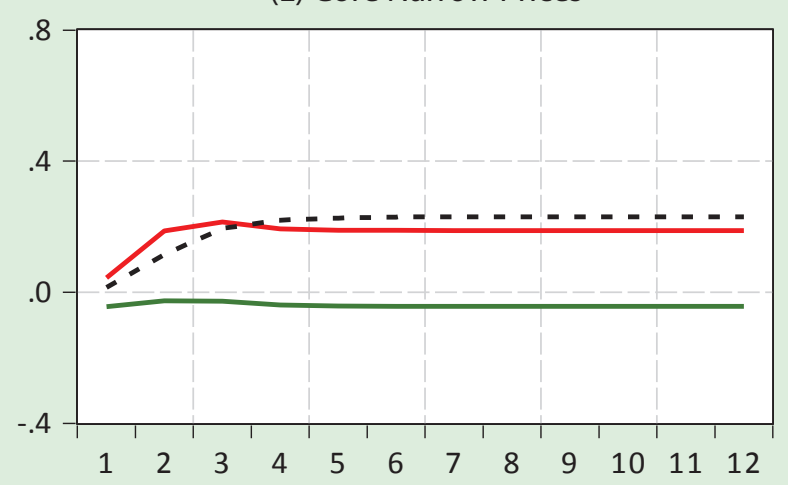

(G) Prices of Import Tradables

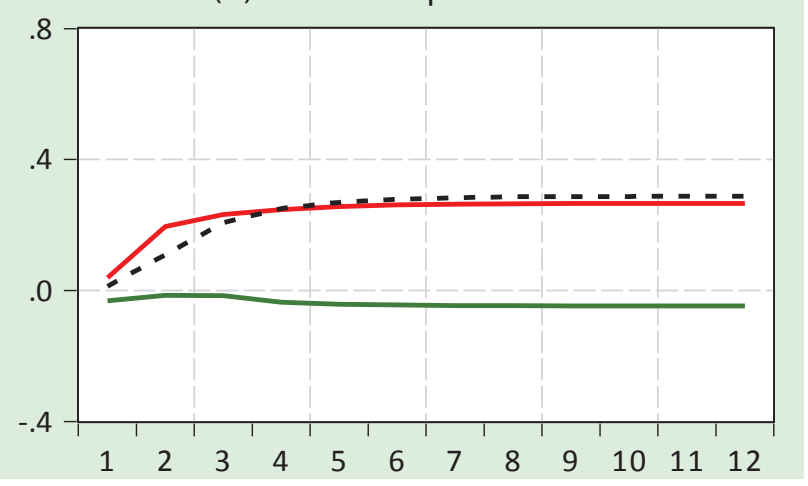

Note. Figures plot cumulative dynamic exchange rate pass-through coefficients for 12 month. 


\section{References}

- Bailliu J., Fujii E. (2004). Exchange Rate Pass-through and the Inflation Environment in Industrialized Countries: An Empirical Investigation. Working Paper, No. 2004-21, Bank of Canada.

- Beckmann E., Fidrmuc J. (2013). Exchange Rate Pass-Through in CIS Countries. Comparative Economic Studies, Vol. 55, No. 4, pp. 705-720. https://doi.org/10.1057/ces.2013.8

- Ben Cheikh N. (2013). Nonlinear Mechanism of the Exchange Rate Pass-Through: Does Business Cycle Matter? CREM UMR CNRS 6211, Working Paper, No. 2013-06, p. 21.

- Bussiere M. (2007). Exchange Rate Pass-Through to Trade Prices: The Role of Nonlinearities and Asymmetries. Working Paper, No. 822, ECB.

- Campa J.M., Goldberg L.S., González-Mínguez J.M. (2005). Exchange-Rate Pass-Through to Import Prices in The Euro Area. Working Paper, No. 11632, pp. 9-36, NBER. https://doi.org/10.3386/w11632

- Coibion O., Gorodnichenko Y. (2015). Inflation Expectations in Ukraine: a Long Path to Anchoring. Visnyk of the National Bank of Ukraine, No. 233, pp. 6-23. https://doi.org/10.26531/vnbu2015.233.006

- Delatte A.-L., López-Villavicencio A. (2012). Asymmetric Exchange Rate Pass-Through: Evidence from Major Countries. Journal of Macroeconomics, Vol. 34, pp. 833-844. https://doi.org/10.1016/j.jmacro.2012.03.003

- Faryna O. (2016). Exchange Rate Pass-Through and Cross-Country Spillovers: Evidence from Ukraine and Russia. BOFIT Discussion paper, No. 14, Bank of Finland, Institute for Economies in Transition.

- Goldberg P., Knetter M. (1997). Goods Prices and Exchange Rates: What Have We Learned? Journal of Economic Literature, No. 35, pp. 1243-1292.

- Koichi M. (2013). Asymmetric Effects of The Exchange Rate on Domestic Corporate Goods Prices. Japan and the World Economy, Vol. 25-26, pp. 80-89.

- Korhonen I., Wachtel P. (2006). A Note on Exchange Rate Pass-Through and Its Asymmetry in CIS Countries. Research in International Business and Finance, Vol. 20, No. 2, pp. 215-226. https://doi.org/10.1016/j.ribaf.2005.09.006

- Marston R.C. (1990). Pricing to Market in Japanese Manufacturing. Journal of International Economics, Vol. 29, No. 3-4, pp. 217-236. https://doi.org/10.1016/0022-1996(90)90031-G

- McCarthy J. (1999). Pass-Through of Exchange Rates and Import Prices to Domestic Inflation in Some Industrialized Economies. Working Papers, No. 79, p. 48, BIS.

- McCarthy J. (2007). Pass-Through of Exchange Rates and Import Prices to Domestic Inflation in Some Industrialized Economies. Eastern Economic Journal, Vol. 33, No. 4, pp. 511-537. https://doi.org/10.1057/eej.2007.38

- Nogueira Jr. R.P., Leon-Ledesma M. (2011). Does Exchange Rate Pass-Through Respond to Measures of Macroeconomic Instability? Journal of Applied Economics, Vol. 14, No. 1, pp. 167-180.

- Nogueira Jr.R.P., Leon-Ledesma M. (2008). Exchange Rate Pass-Through Into Inflation: The Role of Asymmetries and Nonlinearities. Studies in Economics, No. 0801, Department of Economics, University of Kent, p. 44.

- Novikova N., Volkov D. (2012). Modelling Core Inflation in Ukraine in 2003-2012. Economics Education and Research Consortium, Working paper, No. 12-12E.

- Pollard P.S., Coughlin C.C. (2004). Size Matters: Asymmetric Exchange Rate Pass-Through at The Industry Level. Working Paper No. 2003-029C, p. 38, Federal Reserve Bank of St. Louis.

- Shintani M., Terada-Hagiwara A., Yabu T. (2013). Exchange Rate Pass-Through and Inflation: A Nonlinear Time Series Analysis. Journal of International Money and Finance, Vol. 32, pp. 512-527. https://doi.org/10.1016/j.jimonfin.2012.05.024 